\title{
Stimulation of Collateral Vessel Growth by Inhibition of Galectin 2 in Mice Using a Single-Domain Llama-Derived Antibody
}

Maurits R. Hollander, MD;* Matthijs F. Jansen, MD;* Luuk H. G. A. Hopman, MSc; Edward Dolk, PhD; Peter M. van de Ven, PhD; Paul Knaapen, MD, PhD; Anton J. Horrevoets, PhD; Esther Lutgens, MD, PhD; Niels van Royen, MD, PhD

Background-In the presence of arterial stenosis, collateral artery growth (arteriogenesis) can alleviate ischemia and preserve tissue function. In patients with poorly developed collateral arteries, Gal-2 (galectin 2) expression is increased. In vivo administration of Gal-2 inhibits arteriogenesis. Blocking of Gal-2 potentially stimulates arteriogenesis. This study aims to investigate the effect of Gal-2 inhibition on arteriogenesis and macrophage polarization using specific single-domain antibodies.

Methods and Results_Llamas were immunized with Gal-2 to develop anti-Gal-2 antibodies. Binding of Gal-2 to monocytes and binding inhibition of antibodies were quantified. To test arteriogenesis in vivo, Western diet-fed LDLR.(Iow-density lipoprotein receptor)-null Leiden mice underwent femoral artery ligation and received treatment with llama antibodies $2 \mathrm{H} 8$ or $2 \mathrm{C} 10$ or with vehicle. Perfusion restoration was measured with laser Doppler imaging. In the hind limb, arterioles and macrophage subtypes were characterized by histology, together with aortic atherosclerosis. Llama-derived antibodies $2 \mathrm{H} 8$ and $2 \mathrm{C} 10$ strongly inhibited the binding of Gal-2 to monocytes (93\% and 99\%, respectively). Treatment with these antibodies significantly increased perfusion restoration at 14 days (relative to sham, vehicle: $41.3 \pm 2.7 \% ; 2 \mathrm{H} 8: 53.1 \pm 3.4 \%, P=0.016 ; 2 \mathrm{C} 10: 52.0 \pm 3.8 \%, P=0.049$ ). In mice treated with $2 \mathrm{H} 8$ or $2 \mathrm{C} 10$, the mean arteriolar diameter was larger compared with control (vehicle: $17.25 \pm 4.97 \mu \mathrm{m}$; $2 \mathrm{H} 8$ : $17.71 \pm 5.01 \mu \mathrm{m} ; 2 \mathrm{C} 10: 17.84 \pm 4.98 \mu \mathrm{m} ; P<0.001)$. Perivascular macrophages showed a higher fraction of the $\mathrm{M} 2 \mathrm{phenotype}$ in both antibody-treated animals (vehicle: $0.49 \pm 0.24 ; 2 \mathrm{H} 8: 0.73 \pm 0.15, P=0.007 ; 2 \mathrm{C} 10$ : $0.75 \pm 0.18, P=0.006$ ). In vitro antibody treatment decreased the expression of $\mathrm{M} 1$-associated cytokines compared with control $(P<0.05$ for each). Atherosclerotic lesion size was comparable between groups (overall $P=0.59$ ).

Conclusions-Inhibition of Gal-2 induces a proarteriogenic M2 phenotype in macrophages, improves collateral artery growth, and increases perfusion restoration in a murine hind limb model. (J Am Heart Assoc. 2019;8:e012806. DOI: 10.1161/JAHA.119. 012806.)

Key Words: antibody $•$ collateral circulation $•$ macrophage $\cdot$ murine model $\cdot$ perfusion defect

evere atherosclerotic coronary stenosis limits blood flow $\checkmark$ to the downstream myocardium. This perfusion loss can be partly compensated via preexisting collateral arterioles that bypass the arterial stenosis. When needed, these collateral vessels can grow vastly in diameter, a process known as arteriogenesis. ${ }^{1}$ In patients with coronary artery disease, adequate arteriogenesis is strongly associated with less angina pectoris, less adverse remodeling after myocardial infarction, and lower mortality. ${ }^{2-4}$ The magnitude of the arteriogenic response varies greatly among individuals, ${ }^{2}$ and a large proportion of patients with coronary artery disease fail to develop sufficient collateral arteries (collateral flow index

From the Department of Cardiology, VU University Medical Centre, Amsterdam, The Netherlands (M.R.H., M.F.J., L.H.G.A.H., P.K., N.v.R.); Department of Medical Biochemistry, Academic Medical Centre, Amsterdam, The Netherlands (M.F.J., E.L.); QVO B.V., Utrecht, The Netherlands (E.D.); Department of Epidemiology and Biostatistics, VU University, Amsterdam, The Netherlands (P.M.v.d.V.); Department of Molecular Cell Biology and Immunology, VU Medical Center, Amsterdam, The Netherlands (A.J.H.); Institute for Cardiovascular Prevention (IPEK), Ludwig Maximilian's University, Munich, Germany (E.L.); Department of Cardiology, Radboud University Medical Center, Nijmegen, The Netherlands (N.v.R.).

Accompanying Tables S1, S2 and Figure S1 are available at https://www.ahajournals.org/doi/suppl/10.1161/JAHA.119.012806

${ }^{*} \mathrm{Dr}$ Hollander and Dr Jansen contributed equally to this work.

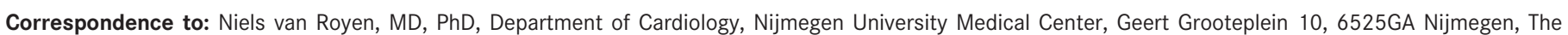
Netherlands. E-mail: niels.vanroyen@radboudumc.nl

Received March 28, 2019; accepted July 17, 2019.

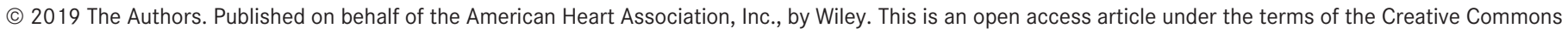

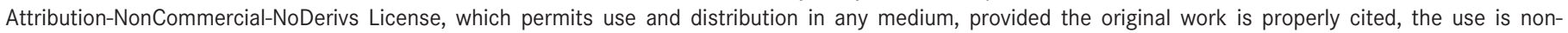
commercial and no modifications or adaptations are made. 


\section{Clinical Perspective}

\section{What Is New?}

- The current study shows for the first time that inhibition of Gal2 (galectin 2) with an antibody stimulates arteriogenesis.

- No effects on atherosclerosis were observed.

\section{What Are the Clinical Implications?}

- Although some patients naturally develop well-functioning collaterals, the majority of patients show insufficient collateral flow in the presence a significant coronary stenosis.

- Stimulation of collateral vessel growth is a promising, adjunctive, pharmacological therapy for patients who are less suitable for invasive revascularization techniques, such as percutaneous coronary intervention.

$\leq 0.25){ }^{5}$ Stimulation of arteriogenesis is a promising treatment option, especially when mechanical revascularization is not possible or is high risk.

Why some patients show a poor arteriogenic response on arterial obstruction is not entirely understood, but certain patient characteristics are linked to poor collateral development. Female sex, diabetes mellitus, and metabolic syndrome, for instance, are associated with poor collateral development. ${ }^{6-8}$ On a cellular level, differences in circulating mononuclear cells_-particularly monocytes and macrophages — play a role. ${ }^{9}$ Studies have shown that a large number of genes are upregulated in monocytes of patients with poorly developed collateral arteries, suggesting these genes inhibit vascular growth. ${ }^{10,11} \mathrm{Gal}-2$ (galectin 2) was found to be one of these inhibiting factors. Galectins are a family of $\beta$-galactosidespecific lectins consisting of 15 different subtypes that play different roles in the immune system, inflammation, and wound healing. ${ }^{12} \mathrm{Gal}-2$ is highly expressed in monocytes of patients with a poorly developed collateral network. In vitro, it was shown that costimulation with Gal-2 inhibits monocyte migration and suppresses the proarteriogenic macrophage M2 phenotype. ${ }^{13}$ This antiarteriogenic effect of treatment with Gal-2 was confirmed in vivo in a murine hind limb model. ${ }^{11}$ To date, the effects of inhibition of Gal-2 remain undetermined. In the current study, we tested the hypothesis that inhibition of Gal-2 would have a proarteriogenic effect. Furthermore, we investigated the effect of Gal-2 inhibition in atherosclerosis.

Because no functional Gal-2-blocking antibodies are available, we developed antibodies against Gal-2 by immunizing llamas. Unlike conventional antibodies, llama antibodies lack a light chain and consist only of the variable domains of heavy chains (VHHs). Consequently, VHHs consist of a single domain, ${ }^{14}$ which makes them more stable, ${ }^{15}$ better soluble, ${ }^{16}$ and easier to produce $^{14}$ than common antibodies. The most potent antibodies were selected in vitro and subsequently tested in vivo in a murine model of combined atherosclerosis and arteriogenesis. ${ }^{17}$

\section{Methods}

The authors declare that all supporting data are available within the article.

\section{Production of Recombinant Gal-2}

Human Gal-2 (hGal-2) and murine Gal-2 (mGal-2) were produced as described previously ${ }^{13}$ Briefly, the frames of recombinant hGal-2 and mGal-2 were synthesized and optimized for Escherichia coli codon usage (BaseClear). The sequences were subsequently cloned into the expression vector of a monomeric mutant of the galectin-1 ( $N$-Gal-1) of $E$ coli BL21 (DE3) cells. After inducing hGal-2 and $\mathrm{mGal}-2$ expression, the bacteria were lysed. Galectins were purified from the supernatant by affinity chromatography on Ni-NTA agarose beads (Qiagen). Finally, the proteins were eluted from the beads and desalted using PD-10 columns (GE Healthcare Life Sciences). Galectin purity was analyzed by SDS-PAGE on a $15 \%$ polyacrylamide gel. After production and purification, Gal-2 was stored at $-80^{\circ} \mathrm{C}$ until further use.

\section{Development of Anti-Gal-2 VHH Antibodies}

\section{Llama immunization and $\mathrm{VHH}$ phage library construction}

For the production of the single-domain antibodies, 2 llamas were immunized with recombinant hGal-2 and $\mathrm{mGal}-2$. Both animals were injected with immunogens (100 $\mu \mathrm{g})$ at days 0,14 , 28 , and 35 . At days 0,28 , and 43 , serum was collected and diluted $1000 \times$, and antibody titers were determined using ELISA. At day 43 , a blood sample $(\approx 200 \mathrm{~mL})$ was taken from each animal, and peripheral blood lymphocytes were collected. RNA was isolated and reverse transcribed into cDNA using the Superscript II Reverse Transcriptase Kit (Invitrogen), after which $\mathrm{VHH}$ genes were amplified with primers specific for the $\mathrm{VHH}$ genes, as previously described. ${ }^{18}$ The $\mathrm{VHH}$ genes were cut with Streptomyces fimbriatus restriction enzyme Sfi 1 plus $E$ coli restriction enzyme Eco91L and cloned into phagemid pUR8100, by transfection to $E$ coli strain TG1. Recovered bacteria were serially diluted and spotted on LB agar plates supplemented with $2 \% \mathrm{w} / \mathrm{v}$ glucose and $100 \mu \mathrm{g} / \mathrm{mL}$ ampicillin in duplicate to determine the size of the libraries.

\section{Phage selection}

The $E$ coli TG1-containing libraries were diluted from the glycerol stock up to an OD600 (optical density at $600 \mathrm{~nm}$ ) of 0.05 in $2 \times$ YT medium containing $2 \% \mathrm{w} / \mathrm{v}$ glucose and $100 \mu \mathrm{g} / \mathrm{mL}$ ampicillin, 
whereas the number of bacteria of the inoculum was $10 \times$ the library size $\left(\approx 10^{8}\right.$ bacteria inoculum) and grown at $37^{\circ} \mathrm{C}$ for 2 hours. Subsequently, $\approx 7 \mathrm{~mL}$ of the cultures were infected with helper phage VCS-M13 using a multiplicity of infection of 100 for 30 minutes at $37^{\circ} \mathrm{C}$. TG1 bacteria were spun down and resuspended into $50 \mathrm{~mL}$ fresh $2 \times$ YT medium supplemented with both ampicillin $(100 \mu \mathrm{g} / \mathrm{mL})$ and kanamycin $(25 \mu \mathrm{g} / \mathrm{mL})$ and grown overnight at $37^{\circ} \mathrm{C}$, on a shaker plate. Produced phages were precipitated from the supernatant of the cultures using polyethylene glycol G-NaCl precipitation.

The phages were used in the panning method directed toward cross-reactive binders against mGal-2 and hGal-2 that could possibly compete for CD14 binding. MaxiSorp plates were coated with hGal-2 or mGal-2 at 2 concentrations (5 and $0.5 \mu \mathrm{g} / \mathrm{mL}$ ) and blocked with $4 \% \mathrm{w} / \mathrm{v}$ Marvel in PBS for 30 minutes. After incubation of the phage library and extensive washing to remove unbound phages, the phages were eluted with a $\mathrm{pH}$ shock. Eluted phages were serially diluted and then used to infect TG1 cells and spotting on LB agar plates supplemented with $2 \% \mathrm{w} / \mathrm{v}$ glucose and $100 \mu \mathrm{g} / \mathrm{mL}$ ampicillin and incubated overnight at $37^{\circ} \mathrm{C}$. Glycerol stock was prepared from all outputs rescued by infection of $E$ coli TG1. Simultaneously, TG1 cultures infected with the output of the selection on $5 \mu \mathrm{g} / \mathrm{mL} \mathrm{hGal-2}$ and $\mathrm{mGal}-2$ (highest coating) were used for phage production of both llama sublibraries to perform a second round of panning selection.

To select for cross-binding, the output phages from the first round on hGal-2 were used for panning on $\mathrm{mGal}-2$ and vice versa. In addition to the $\mathrm{pH}$ shock for elution, bound phages were also eluted by incubation with PBS containing $5 \mu \mathrm{g} / \mathrm{mL}$ CD14. Eluted phages were serially diluted and then used to infect TG1 cells and spotted on LB agar plates supplemented with $2 \% \mathrm{w} / \mathrm{v}$ glucose and $100 \mu \mathrm{g} / \mathrm{mL}$ ampicillin, and then incubated overnight at $37^{\circ} \mathrm{C}$ to determine the enrichment of binding phages after the second round of selection. Simultaneously, TG1 cultures infected with the output of the different selection methods were used for picking monoclonal VHHs in 2 master plates containing a selection of 184 single clones (92 per llama).

\section{Production of periplasmic fraction}

The master plates were cultivated at $37^{\circ} \mathrm{C}$ for 3 hours, after which $1 \mathrm{mmol} / \mathrm{L}$ isopropyl $\beta$-D-1-thiogalactopyranoside was added for $\mathrm{VHH}$ production. Periplasmic fractions were prepared by collecting the bacteria by centrifugation and resuspension into $120 \mu \mathrm{L}$ PBS. After freezing, bacteria were thawed and centrifuged to separate the soluble periplasmic fraction containing the $\mathrm{VHHs}$ and cell debris.

\section{Gal-2 binding assay}

To test the binding activity and cross-reactivity of the VHHs to hGal-2 and mGal-2, $100 \mathrm{ng} /$ well of each antigen was coated on a MaxiSorp plate overnight in PBS at $4^{\circ} \mathrm{C}$. After washing of the wells and a blocking step using $2 \%$ milk powder (Marvel) in PBS, $25 \mu \mathrm{L}$ of the periplasmic fractions in $100 \mu \mathrm{L} 1 \% \mathrm{w} / \mathrm{v}$ marvel PBS were added to each well and incubated for 90 minutes. After washing, the $\mathrm{VHH}$ were detected with an anti-myelocytomatosis oncogene (monoclonal antibody 9E10) and a donkey antimouse IgG coupled to horseradish peroxidase. $\mathrm{VHH}$ binding was quantified by the colorimetric conversion of $\mathrm{O}$-phenylenediamine in the presence of $\mathrm{H}_{2} \mathrm{O}_{2}$.

\section{Monocyte binding assay}

To select periplasmic fractions for subcloning, a binding assay was performed in which the inhibitory effect on the binding of Gal-2 to monocytes was quantified by flow cytometry. For this, galectins were labeled with biotin (Sigma-Aldrich) in $\mathrm{N}$-hydroxysuccinimide solution (Sigma-Aldrich). Biotinylated Gal-2 was preincubated with VHHs diluted in PBS $(50 \mu \mathrm{g} / \mathrm{mL})$ for 30 minutes at room temperature. Subsequently wild-type murine bone marrow was resuspended in PBS containing the preincubated Gal-2 and $\mathrm{VHHs}$ and incubated for 60 minutes on ice. After washing, the cells were incubated with streptavidin-Alexa Fluor 488 (1:400; Invitrogen) for 30 minutes on ice. Background staining was determined by omitting the biotinylated Gal-2. After washing, the cells were analyzed by flow cytometry using a Cyan ADP High Performance Research Flow Cytometer (Beckman Coulter). The data were analyzed using Flowlo software (Becton Dickinson). The monocyte subset was gated based on the forward/side scatter properties. After subcloning the VHHs, the monocyte binding assay was repeated to investigate the effect of the subcloning procedure on binding inhibition capacity of the antibodies.

\section{Subcloning and production}

Based on the results from the monocyte binding assays and binding specificity, 5 separate VHH clones were selected (1B11, $1 \mathrm{C} 11,2 \mathrm{D} 8,2 \mathrm{H} 8$, and 2C10). These $5 \mathrm{VHH}$ were subcloned into the pMEK222 E coli expression vector containing the FLAG-His (histidine) tag, and the clones were sequenced to identify the sequence families of the different VHHs. Four different sequences were found, as $1 \mathrm{~B} 11$ and $1 \mathrm{C} 11$ had an identical DNA sequence. The differences between the complementaritydetermining regions of the 4 clones indicate that they hit different epitopes on Gal-2. VHHs were produced in large culture and purified using metal affinity chromatography (Talon; GE Healthcare Life Sciences). VHH proteins were analyzed on SDS-PAGE for purity and integrity. All $4 \mathrm{VHHs}$ were shown to be $>90 \%$ pure and with proper integrity.

\section{Murine Hind Limb Model}

\section{Animals}

All animal procedures were approved by the Institutional Animal Experimental Ethics Committee and the Central 
Committee on Animal Experimentation and conform to the guidelines from Directive 2010/63/EU of the European Parliament. To study the growth of preexisting collateral arteries without inducing hypoxia, a murine hind limb model was used with a C57BL/6 mouse strain. ${ }^{19}$ In total, we used 64 C57BI/6 LDLR-/- (low-density lipoprotein receptornull).Leiden mice ${ }^{20}$ (32 male, 32 female) aged 10 to 12 weeks (TNO Metabolic Health Research). All mice received a high-fat "Western" diet $(0.15 \%$ cholesterol and $16 \%$ fat; Altromin) for 8 weeks to induce an atherogenic phenotype. ${ }^{21}$ Six weeks after the start of the Western diet, the femoral artery was unilaterally ligated and animals received their allocated treatment.

\section{Femoral artery ligation}

The femoral artery was permanently ligated unilaterally, as described previously. ${ }^{22}$ In short, the mice were weighed and anesthetized by intraperitoneal injection of dexmedetomidine $(1.0 \mathrm{mg} / \mathrm{kg}$; Dexdomitor, Orion) and ketamine $(70.0 \mathrm{mg} / \mathrm{kg}$; Alfasan Pharma). Subsequently, both paws were depilated. The right femoral artery was carefully dissected from the femoral nerve and ligated with a double suture (Prolene, 7-0 nonabsorbable; Ethicon). On the left hind limb, a sham operation was performed in which the femoral artery was dissected but not ligated. Finally, the skin was sutured (coated Vicryl, 7-0; Ethicon), and anesthesia was antagonized with an intraperitoneal injection of atipamezole ( $0.5 \mathrm{mg} / \mathrm{kg}$; Atipam, Orion). To minimize postsurgical pain, buprenorphine was administered subcutaneously (2.0 mg/kg; MSD Animal Health).

\section{Treatment}

Postoperatively, mice were treated for 2 weeks with antibody $2 \mathrm{H} 8$, antibody $2 \mathrm{C} 10$, or vehicle, in equally large groups and stratified by sex. Both antibodies are cross-binding (murine and human) anti-Gal-2 antibodies. Antibody treatment consisted of a charging dose directly after surgery, followed by a daily maintenance dose. Daily administration was chosen because of the relatively high blood clearance of $\mathrm{VHHs} .{ }^{14} \mathrm{The}$ charging dose consisted of either $0.51 \mathrm{mg}$ purified $2 \mathrm{H} 8$ antiGal-2 antibody or $0.51 \mathrm{mg}$ purified 2C10 anti-Gal-2 antibody, diluted in sterile saline solution. The maintenance dose consisted of $0.015 \mathrm{mg}$ for both antibodies. Control mice received isovolumetric intraperitoneal injections of sterile $0.9 \%$ sodium chloride solution. All treatments were given intraperitoneal injections with extra-thin needles to minimize injection trauma (Microfine, 29G; Becton Dickinson).

\section{Laser Doppler perfusion imaging}

The perfusion of both paws was quantified using a laser Doppler perfusion imager (Moor Industries). Animals were scanned before and after the surgical procedure and 2, 7, and 14 days after femoral artery ligation. Mice were anesthetized by intraperitoneal injection of dexmedetomidine $(1.0 \mathrm{mg} / \mathrm{kg}$; Orion) and ketamine (70.0 mg/kg; Alfasan Pharma). Animals were placed on a heating plate to minimize body temperature variation. All scans were performed in a sealed room with controlled, stable temperature and lighting. After scanning, anesthesia was antagonized with atipamezole $(0.5 \mathrm{mg} / \mathrm{kg}$; Orion). Dedicated software was used to calculate perfusion (MoorLDI software; Moor Instruments). To account for any variations that, despite precautions, could influence the measurements, the perfusion in the foot was expressed as a ratio of right (ligated) to left (sham) hind limb, as described previously. ${ }^{23}$

\section{Histology}

Fourteen days after the surgical procedure, the mice were euthanized by carbon dioxide inhalation, after which the adductor muscle and aortic roots were harvested to investigate arteriolar remodeling, macrophage characteristics, and atherosclerosis. Tissue was fixed in $4 \%$ formalin, embedded in paraffin, cut into sections ( $3 \mu \mathrm{m}$ for muscle tissue, $4 \mu \mathrm{m}$ for aortic tissue), and mounted on coated glass slides (Starfrost; Knittel).

To analyze arteriolar remodeling, adductor muscle sections were deparaffinized, pretreated with heat-induced epitope retrieval in TRIS-EDTA buffer ( $\mathrm{pH}$ 9.0), and incubated with an rabbit antimouse $\alpha$-SMA ( $\alpha$-smooth muscle actin) antibody (1:200, 60 minutes at room temperature; ab32575, Abcam). As a secondary antibody a horseradish peroxidase-conjugated goat antirabbit antibody was used $(1: 100,30$ minutes at room temperature; p0448, Dako). Thereafter, DAB (3,3'diaminobenzidine) peroxidase was used as substrate, followed by a counterstaining using hematoxylin. Slides were automatically covered with the Tissue-Tek Film Coverslipper (Sakura Finetek Europe) and scanned using the Panoramic DESK scanner (3DHistech). Vessel diameters were quantified with the use of dedicated image processing software (Panoramic Viewer [3DHistech] and Image] [National Institutes of Health]). Minimal vessel diameter was used to approximate true vessel diameter in obliquely cut vessels assuming vascular circularity. Arterioles were identified as $\mathrm{SMA}^{+}$vessels with a diameter of 6 to $30 \mu \mathrm{m}$.

To investigate the effect of treatment on perivascular macrophages, slides were pretreated with heat-induced epitope retrieval and incubated with $10 \%$ normal goat serum (30 minutes at room temperature). Slides were incubated with an anti-SMA antibody (as described) to identify arterioles, with an anti-F4/80 antibody for the detection of macrophages (1:200, overnight at $4^{\circ} \mathrm{C}$, rat antimouse $\mathrm{F} 4 / 80$ antibody; MCA497, Bio-Rad), and with an anti-MR (anti-mannose receptor) for the identification of $M 2$ macrophages (1:50, 60 minutes at room temperature, rabbit antimouse MR; ab64693, Abcam). The following secondary antibodies were 
used: goat antirabbit Alexa 647 (SMA), goat antirat Alexa 555 (F4/80), and goat antirabbit Alexa 488 (MR). Cell nuclei were stained with DAPI (4',6-diamidino-2-phenylindole; 1:200 000, 10 minutes at room temperature; Invitrogen). Slides were covered as described earlier. For the quantification of macrophages, slides were analyzed with the Leica fluorescence microscope (DM6000; Leica Microsystems). For each mouse, 10 arterioles per hind limb were randomly selected and photographed (field size $224.3 \times 167.54 \mu \mathrm{m}$ ). Per image, field macrophages $\left(\mathrm{F} 4 / 80^{+}\right)$and $\mathrm{M} 2$ macrophages (F4/80 and $\mathrm{MR}^{+}$) were counted and expressed as number per field.

For the investigation of atherosclerotic plaque burden, the aortic root was cut and mounted as described earlier and set in an incubator at $60^{\circ} \mathrm{C}$ overnight. Ten consecutive slides with $40 \mu \mathrm{m}$ in between were selected and subsequently deparaffinized automatically, stained (hematoxylin and eosin), and covered using the Tissue-Tek Prisma and Film system (Sakura Finetek Europe). Slides were digitally scanned and analyzed as the arterial remodeling sections. Plaque area was identified based on morphologic characteristics. Atherosclerosis was defined as the mean total supravalvular atherosclerotic plaque area per slide. Quantification of all (immuno)histochemical analyses was performed in a blinded fashion.

\section{Downstream signaling in effector cells}

To gain mechanistic insight in the arteriogenic effect of antiGal-2 treatment, the downstream effect of Gal-2 on human and murine leukocytes cells was investigated, with or without the presence of the antibodies $2 \mathrm{H} 8$ and $2 \mathrm{C} 10$ or an irrelevant anti-HIV VHH antibody, which served as a control.

Murine effector cells were obtained from wild-type murine isolated bone marrow, which was thawed, washed, and resuspended in PBS with $1 \%$ BSA and left to rest for 60 minutes at $4^{\circ} \mathrm{C}$ to limit early activation. After resting, the cells were suspended in DMEM containing $10 \%$ FCS, $1 \%$ penicillin-streptomycin, and polymyxin B $(20 \mu \mathrm{g} / \mathrm{mL})$ before plating in wells (100 000 cells/well). Wells were incubated for 3 hours at $37^{\circ} \mathrm{C}$ in medium only, mGal-2, mGal-2 with $2 \mathrm{C} 10$ antibody, mGal-2 with $2 \mathrm{H} 8$ antibody, mGal-2 with an irrelevant control $\mathrm{VHH}$ antibody, $2 \mathrm{C} 10$ antibody alone, $2 \mathrm{H} 8$ antibody alone, or control $\mathrm{VHH}$ antibody alone.

Human monocytes were isolated from fresh peripheral blood using a 2-step gradient isolation, as described previously. ${ }^{13}$ In short, peripheral blood mononuclear cells were isolated from whole blood from 2 anonymous healthy donors, using Ficoll density gradient (Lymphoprep; Axis Shield). After this, the monocytes were subsequently separated by a second gradient isolation, this time using a Percoll solution (GE Heathcare). After washing, cells were suspended in RPMI 1640 medium containing 10\% heat-inactivated FCS, $1 \%$ penicillin-streptomycin, and polymyxin B $(20 \mu \mathrm{g} / \mathrm{mL})$. Human monocytes were incubated for 3 hours at $37^{\circ} \mathrm{C}$ in medium only, hGal-2, hGal-2 with 2C10 antibody, hGal-2 with $2 \mathrm{H} 8$ antibody, hGal-2 with an irrelevant control VHH antibody, 2C10 antibody alone, $2 \mathrm{H} 8$ antibody alone, or control $\mathrm{VHH}$ antibody alone.

After the incubation period, the cells were collected and RNA was isolated, according to the manufacturer's instructions (High Pure Isolation Kit; Roche). In addition, cDNA was synthesized using the Thermo Fisher High-Capacity cDNA Reverse Transcription Kit, according to the manufacturer's instructions. Nucleic acid concentrations were measured with a Nanodrop ND-1000 spectrophotometer.

Quantitative real-time polymerase chain reaction (PCR) was carried out using the following primers: IFN- $\beta$ (interferon $\beta$ ), IL6 (interleukin 6), and TNF (tumor necrosis factor); GAPDH was used as a reference gene (Table S1). In summary, $2 \mu \mathrm{L}$ of diluted cDNA was mixed in triplicate with $300 \mathrm{nmol} / \mathrm{L}$ SYBR Green Fast Mix (Invitrogen Life Technologies) and $300 \mathrm{nmol} / \mathrm{L}$ of each primer. Quantitative PCR was performed on the ViiA 7 Real-Time PCR system (Thermo Fisher). Per incubation sample, all target gene expression levels related to the reference gene GAPDH. All quantitative PCR analyses were repeated 2 times ( 3 in total). Data were analyzed with dedicated PCR software ${ }^{24}$ (LinRegPCR, v2016; Amsterdam University Medical Center, Heart Failure Research Center). Expression levels are displayed as a fold increase compared with the control sample incubated with medium only.

\section{Statistical Analysis}

Normality of continuous variables was tested by means of Shapiro-Wilk test. Normally distributed data are displayed as mean \pm SD. For the perfusion restoration analysis, the overall treatment effect was calculated with a repeated-measures ANOVA; for post hoc analysis, a 2-sided Dunnett test was used. Perfusion restoration analysis per time point was calculated with a mixed model, using time, treatment, and the interaction of time and treatment as the input. Time was considered a categorical variable. Only mouse identification number was considered random. For the histological analyses between treatment groups, ANOVA was used ( $P$-trend for all groups). When statistically significant, a 2-sided Dunnett test for post hoc analysis was used comparing the antibody groups to control. Effects between antibody groups were compared using a Bonferroni post hoc test. For the comparison between sham and ligated hind limb, a Student $t$ test was used. Arteriolar remodeling analysis was performed on a per-vessel basis. For the statistical analysis of expression levels, ANOVA was used with the irrelevant $\mathrm{VHH}$-treated samples as control. Statistical analysis was performed using SPSS software (IBM SPSS Statistics 20; IBM Corp). $P<0.05$ was considered statistically significant. 


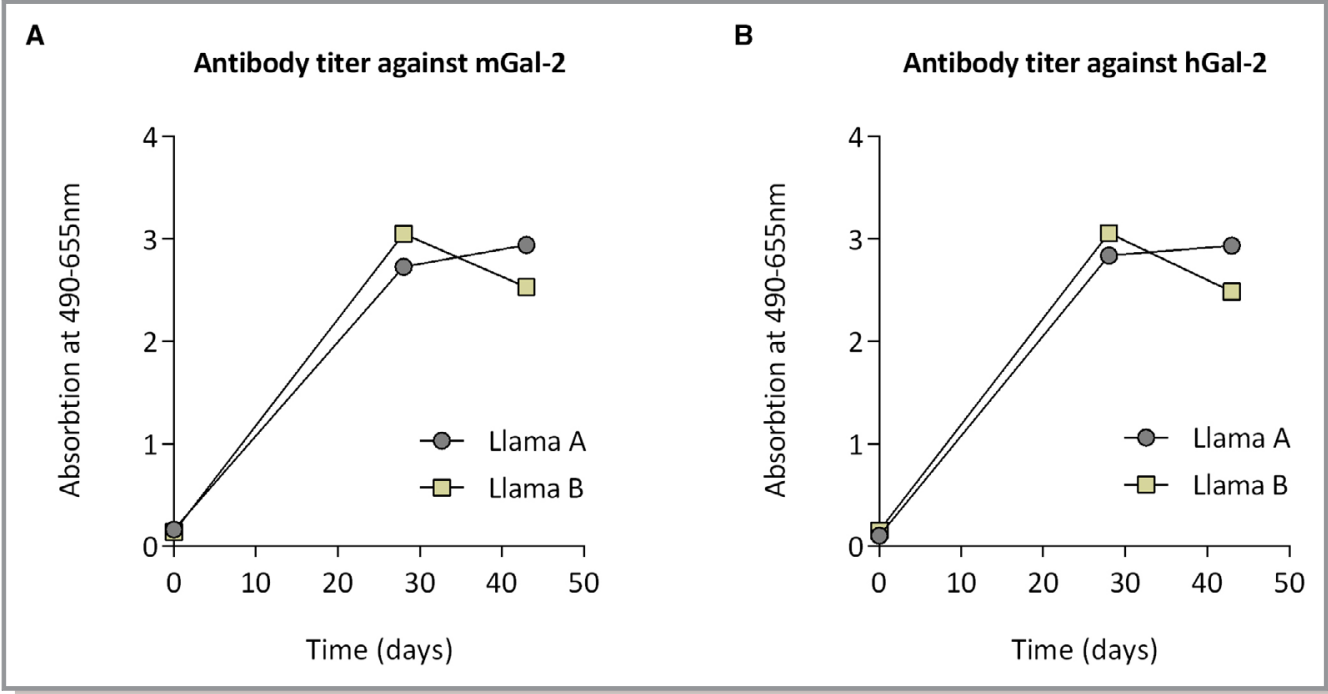

Figure 1. Llama immune response. Antibody titers of both immunized llamas to recombinant mGal-2 (A) and recombinant hGal-2 (B), measured in the sera collected on days 0,28 , and 43 of the immunization period. Serum is diluted $1000 \times$ before measurement. hGAL-2 indicates human galectin 2; mGal-2, murine galectin 2 .

\section{Results}

\section{Development of Single-Domain Antibodies Against Gal-2}

Both Ilamas showed clear immune responses to both hGal-2 and $\mathrm{mGal}-2$ with maximum titers at days 28 and 43 (Figure 1). After RNA extraction and subcloning, the libraries consisted of $4.8 \times 10^{7}$ and $1.6 \times 10^{7}$ transformants in Ilama A and llama B respectively. Isolation of antibodies that cross-react with both mGal-2 and hGal-2 and that compete with CD14 binding yielded 184 antibody candidates.

\section{Binding Specificity of VHHs}

The ELISA binding assay revealed that the $\mathrm{VHHs}$ originating from one of the 2 llamas did not show detectable binding to both antigens (data not shown). From the 92 preselected clones of the other llama, 41 antibodies showed sufficient binding to hGal-2 and/or mGal-2. Thirty-one VHHs showed cross-binding to both hGal-2 and $\mathrm{mGal}-2$. Five $\mathrm{VHHs}$ were specifically bound to hGal-2, and $5 \mathrm{VHHs}$ were specific to mGal-2 (Table S2).

\section{Inhibition of Binding of Gal-2 to Monocytes}

Based on the ELISA signals, 41 periplasmic fraction $\mathrm{VHHs}$ were tested for their capacity to inhibit the binding of Gal-2 to murine monocytes. Twenty-eight (68\%) of the 41 tested $\mathrm{VHHs}$ inhibited the binding of Gal-2 to monocytes compared with unconstrained stimulation with Gal-2. Maximal inhibition was achieved with $\mathrm{VHH} 2 \mathrm{C} 10$, which reduced the inhibition of Gal2 to murine monocytes by $77 \%$ (Figure $2 \mathrm{~A}$ ).

Based on these results and binding specificity, the 5 most potent $\mathrm{VHH}$ clones were selected for further subcloning and production. Of these $5 \mathrm{VHHs}, 1$ was human specific (2D8), 2 were mouse specific (1B11 and $1 \mathrm{C} 11$ ), and 2 were cross-binding (2H8 and $2 \mathrm{C} 10)$. After subcloning the periplasmic $\mathrm{VHH}$ fractions into the pMEK222 E coli expression vector, DNA sequencing revealed that 2 clones (1C11 and $1 \mathrm{~B} 11)$ had identical protein sequences, leaving 4 unique clones suitable for further processing $(2 \mathrm{H} 8,2 \mathrm{C} 10,1 \mathrm{C} 11$, and 2D8). After production and purification, all $4 \mathrm{VHHs}$ showed excellent purity (Figure S1) and no alterations in binding specificity (data not shown).

The 4 subcloned VHHs were also tested for their inhibitory effect on the binding of Gal-2 on murine monocytes. All 4 subcloned VHHs retained their capacity to inhibit the binding of mGal-2 to murine monocytes. Moreover, $\mathrm{VHHs} 2 \mathrm{H} 8,1 \mathrm{C} 11$, and $2 \mathrm{C} 10$ showed increased binding inhibition of Gal-2 compared with prior subcloning, production, and purification (Figure 2B). Based on binding specificity, cross-binding VHHs $2 \mathrm{H} 8$ and $2 \mathrm{C} 10$ were selected for the consecutive in vivo experiments.

\section{Gal-2 Inhibition Restores Hind Limb Perfusion}

Sixty-four animals underwent femoral artery ligation, and no complications occurred during surgery. In the period following the ligation procedure, 11 animals died. Two animals in the $2 \mathrm{C} 10$ group died because of defective cage-heating equipment. Based on humane end points, 3 animals were euthanized prematurely. 


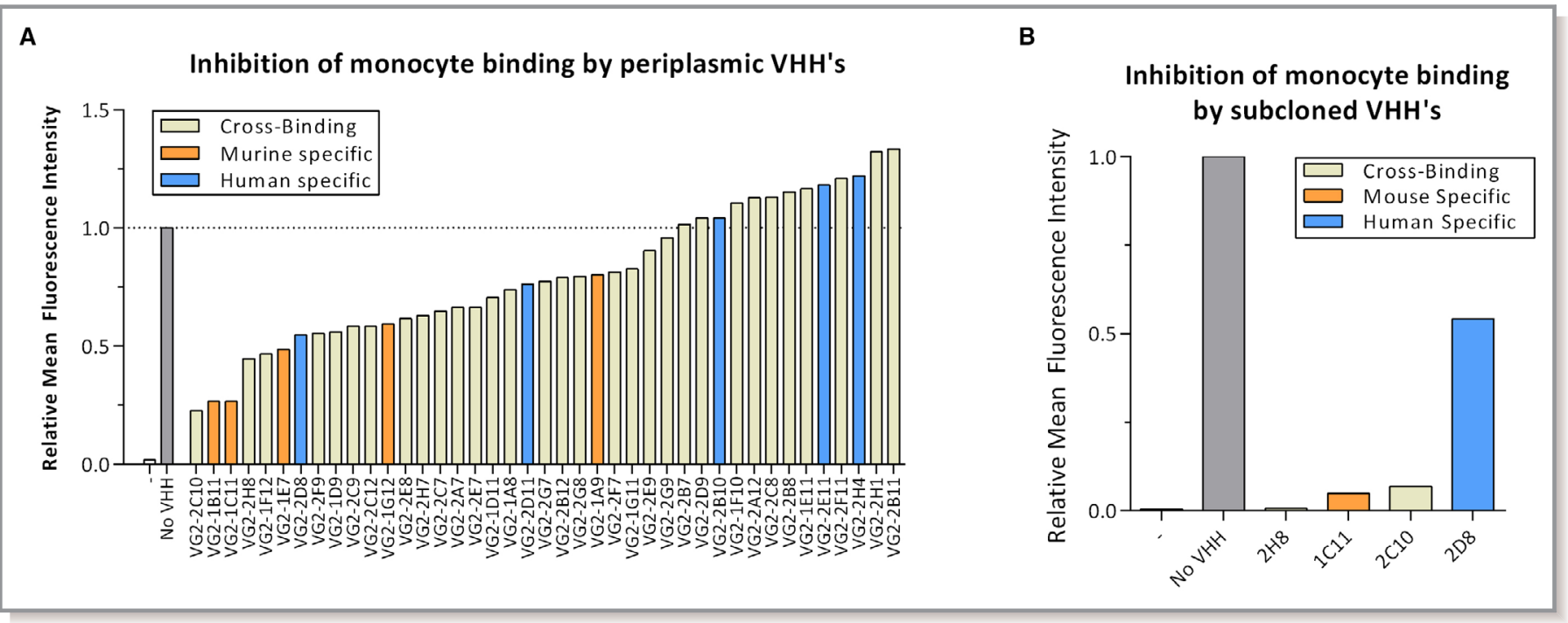

Figure 2. Inhibition of binding of Gal-2 (galectin 2) to murine monocytes by single-domain antibodies. Binding of labeled Gal-2 to murine monocytes, analyzed by flow cytometry, and the influence of single-domain antibodies (VHHs). A, Cells ( $10^{5}$ cells $/$ well) were incubated with either Gal-2 alone (no VHH), Gal-2 with 1 of the 41 selected periplasmic fraction VHHs, or without any addition (-). B, Cells were incubated with no addition, Gal-2 alone (gray bars), or Gal-2 with $2 \mathrm{H} 8,1 \mathrm{C} 11,2 \mathrm{C} 10$, or 2D8. VHH indicates variable domain of heavy chains.

The other animals died spontaneously; in these animals, macroscopic autopsy did not reveal any causes of death related to the surgical procure. Premature death occurred at equal rates in the control group $(\mathrm{n}=7,22 \%)$ and among mice treated with $2 \mathrm{C} 10(\mathrm{n}=2,14 \%)$ or $2 \mathrm{H} 8(\mathrm{n}=2,14 \% ; P=0.69$ for trend between groups).

Directly after surgery, hind limb perfusion at the ligated side was $16.2 \%$ on average compared with the nonligated paw, and this result did not differ between groups $(P=0.68)$. In the 2 weeks after surgery, hind limb perfusion was restored significantly over time in all groups (repeated-measures ANOVA: $F[3,42]=54.2, P<0.0001$ ). Fourteen days after femoral artery ligation, both $2 \mathrm{C} 10$ - and $2 \mathrm{H} 8-$ treated animals had higher hind limb perfusion compared with control (control: $41.3 \pm 2.7 \%, \mathrm{n}=25 ; 2 \mathrm{H} 8$ : $53.1 \pm 3.4 \%, \mathrm{n}=14$, $P=0.016 ; 2 \mathrm{C} 10: 52.0 \pm 3.8 \%, \mathrm{n}=11, P=0.049$; Figure 3). Perfusion data of other time points are displayed in Table 1.
A

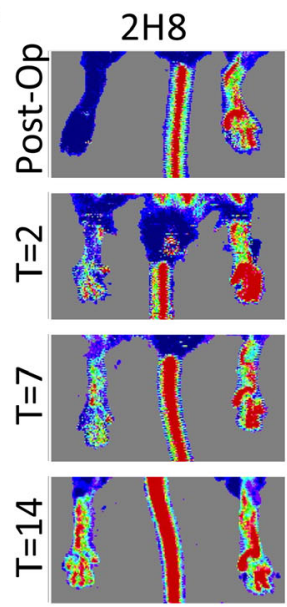

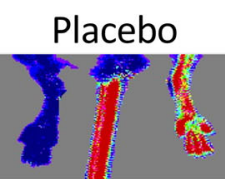
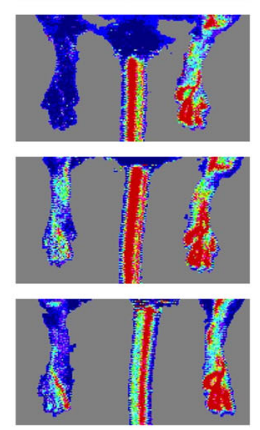

B

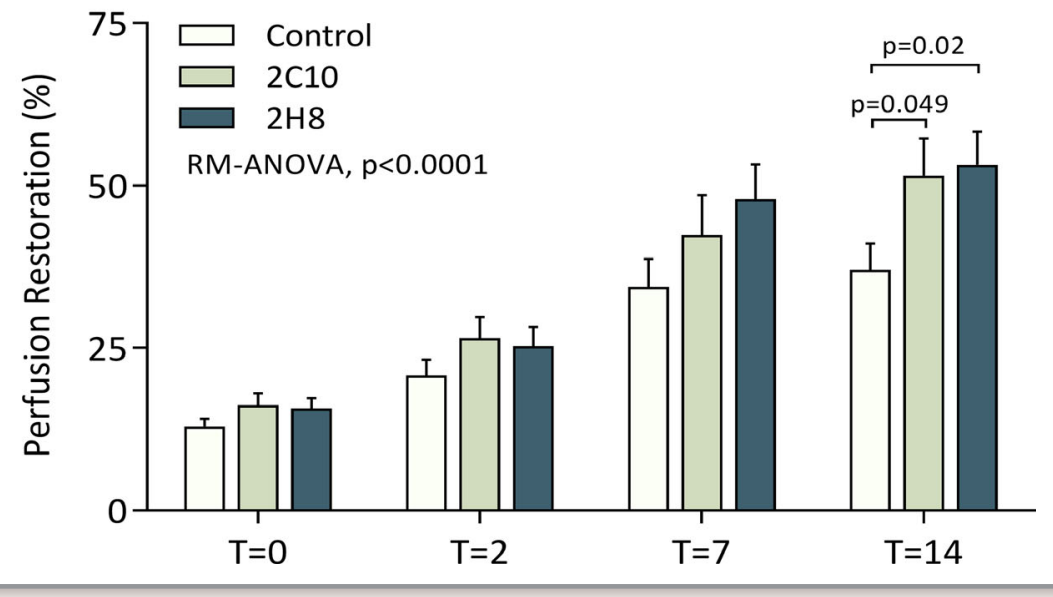

Figure 3. Perfusion restoration. Restoration of hind limb perfusion after femoral artery ligation. Perfusion was quantified noninvasively by laser Doppler perfusion imaging (A). Measurements were taken postoperatively (post-op) and 2, 7, and 14 days after femoral artery ligation. Restoration of hind limb perfusion was significantly increased in animals treated with either $2 \mathrm{H} 8$ ( $n=14$ ) or $2 \mathrm{C} 10$ ( $n=14)$ compared with control $(n=25)(B)$. Repeated-measures ANOVA (RM-ANOVA) was used for overall analysis; a mixed model using time and treatment as input was used for time point analysis. 
Table 1. Hind Limb Perfusion Restoration Over Time

\begin{tabular}{|l|l|l|l|l|l|}
\hline Time Point & Control & $2 \mathrm{H} 8$ & $P$ Value* & $2 \mathrm{C} 10$ & $P$ Value $^{*}$ \\
\hline $\begin{array}{c}\text { Postop } \\
(\mathrm{T}=0)\end{array}$ & $14.5 \pm 2.3$ & $15.8 \pm 3.2$ & 1.00 & $17.8 \pm 3.2$ & 0.82 \\
\hline $\mathrm{T}=2$ & $23.4 \pm 2.6$ & $26.0 \pm 3.2$ & 1.00 & $27.2 \pm 3.7$ & 0.81 \\
\hline $\mathrm{T}=7$ & $37.9 \pm 2.6$ & $46.3 \pm 3.3$ & 0.10 & $42.9 \pm 3.8$ & 0.56 \\
\hline $\mathrm{T}=14$ & $41.3 \pm 2.7$ & $53.1 \pm 3.4$ & $0.02^{\dagger}$ & $52.0 \pm 3.8$ & $0.049^{\dagger}$ \\
\hline
\end{tabular}

Data are presented as the ratio of perfusion of the ligated side to the perfusion of the sham side (\%). Postop indicates directly after femoral artery ligation; T, time. ${ }^{*} P$ values represent the differences between the antibody treatment and control. $p<0.05$ was considered statistically significant.

\section{Gal-2 Inhibition Promotes Collateral Artery Remodeling}

Hind limb tissue was collected from 37 animals 2 weeks after the surgical procedure for histological analysis. To investigate the etiology of the perfusion restoration, we quantified the arteriolar diameters in the hind limbs. Arteriolar diameters in the ligated limb significantly differed between groups (ANOVA, $P<0.0001)$. The mean diameter in the control group (17.25 $\pm 4.97 \mu \mathrm{m}, \mathrm{n}=10$ ) was lower than those in both the $2 \mathrm{H} 8$ group $(17.71 \pm 5.01 \mu \mathrm{m}, \mathrm{n}=14 ; P<0.0001)$ and the $2 \mathrm{C} 10$ group (17.84 $44.98 \mu \mathrm{m}, \mathrm{n}=11 ; P<0.001)$. Vessel diameters were comparable between the $2 \mathrm{H} 8$ and $2 \mathrm{C} 10$ groups $(P=0.65)$. In the sham-operated hind limb, arterial vessel diameters did not differ between groups (ANOVA, $P=0.10$; control: 17.29 \pm 5.12 ; 2H8: $17.53 \pm 4.96$; 2 C 10: 17.46 \pm 4.98$)$. In all treatment groups, the arteriolar diameter was significantly different between sham and ligation ( $P>0.001$ in all groups; Table 2).

\section{Perivascular macrophage characterization}

Quantification of the macrophages in the ligated hind limbs (Figure 4A-4E) revealed that antibody-treated animals had similar mean numbers of perivascular macrophages compared with control (ANOVA, $P=0.25$; control: $0.81 \pm 0.57, \mathrm{n}=10 ; 2 \mathrm{H} 8$ $[1.19 \pm 0.60, \mathrm{n}=14]$ versus control, $P=0.19 ; 2 \mathrm{C} 10[0.92 \pm 0.54$, $\mathrm{n}=11$ ] versus control, $P=0.86)$. The mean number of perivascular macrophages did not differ between 2H8- and 2C10-treated animals ( $P=0.77$; Figure $4 \mathrm{~F}$ ). Immunohistological characterization showed that the perivascular macrophages of antibodytreated mice consisted of a significantly larger fraction of $M 2$ macrophages compared with control (ANOVA $P=0.004$; control: $0.49 \pm 0.24 ; 2 \mathrm{H} 8[0.73 \pm 0.15]$ versus control, $P=0.007 ; 2 \mathrm{C} 10$ $[0.75 \pm 0.18]$ versus control, $P=0.006$; Figure $4 \mathrm{G})$. The fractions of M2 macrophages were similar between both antibody groups $(P=1.00)$. In the left hind limb, where a sham procedure was performed, mean numbers of perivascular macrophages and M2 macrophage fractions were similar in all 3 groups (control [0.78 \pm 0.42 ], $2 \mathrm{H} 8$ [1.09 \pm 0.90$]$, and $2 \mathrm{C} 10$ [1.08 \pm 0.69$]$, ANOVA $P=0.49$; M2 fraction: control [0.33 \pm 0.26$], 2 \mathrm{H} 8$ [0.48 \pm 0.27$]$, and $2 \mathrm{C} 10 \mathrm{~L}[0.44 \pm 0.17]$, ANOVA $P=0.25)$. Notably, only in the antibody-treated groups did the macrophage characteristics differ between sham and ligated hind limbs (Figure 4G).

\section{Atherosclerosis}

Supravalvular atherosclerotic plaque was visible in all investigated animals $(n=34)$ and showed a xanthomatous morphology consisting of predominantly foam cells (Figure $5 \mathrm{~A}$ ). After 8 weeks of Western diet, the total plaque area in the control group was $4.41 \times 10^{4} \pm 2.8 \times 10^{4}(n=10)$. Treatment with $2 \mathrm{H} 8$ or $2 \mathrm{C} 10$ did not affect plaque area $(2 \mathrm{H} 8$ :

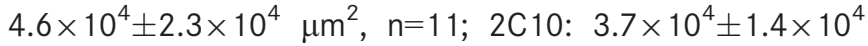
$\mu \mathrm{m}^{2}, \mathrm{n}=13$; between groups $P=0.67$; Figure $5 \mathrm{~B}$ ). No evidence of plaque rupture was seen in any animals.

\section{RNA Expression of Gal-2-Induced Genes}

To confirm the findings of the macrophage polarization analysis from the in vivo experiments and to further investigate the mechanism behind the polarizing effect, we performed a functional mRNA assay on both murine and human cells, using the M1-phenotype markers INF- $\beta$, IL6, and TNF- $\alpha .{ }^{25}$ After stimulation with either hGal-2 of mGal-2, the expression of these genes was strongly increased compared

Table 2. Arteriolar Remodeling

\begin{tabular}{|c|c|c|c|c|c|}
\hline \multirow[b]{2}{*}{ Treatment } & \multicolumn{2}{|l|}{ Ligation } & \multicolumn{2}{|l|}{ Sham } & \multirow{2}{*}{$\begin{array}{l}P \text { Value of Difference Between } \\
\text { Ligation and Sham Per Treatmen } \\
\text { Group }\end{array}$} \\
\hline & $\begin{array}{l}\text { Mean Arteriolar } \\
\text { Diameter }(\mu \mathrm{m})\end{array}$ & $P$-Trend $d^{*}<0.001$ & $\begin{array}{l}\text { Mean Arteriolar } \\
\text { Diameter }(\mu \mathrm{m})\end{array}$ & $\begin{array}{l}\text { Significance Between Groups } \\
P \text {-Trend } 0.10^{\dagger}\end{array}$ & \\
\hline $2 \mathrm{H} 8$ & $17.7 \pm 5.0$ & vs control: $<0.001$ & $17.5 \pm 5.0$ & $N A^{\dagger}$ & $<0.001$ \\
\hline $2 \mathrm{C} 10$ & $17.8 \pm 5.0$ & $\begin{array}{l}\text { vs control: }<0.001 \\
\text { vs } 2 \mathrm{H} 8: 0.65\end{array}$ & $17.5 \pm 5.0$ & $N A^{\dagger}$ & $<0.001$ \\
\hline
\end{tabular}

NA indicates not applicable.

* $P$ value for trend across treatment groups and post hoc analysis using Bonferroni correction.

${ }^{\dagger}$ No post hoc analyses were conducted because the significance level for $P$-trend was not met. 

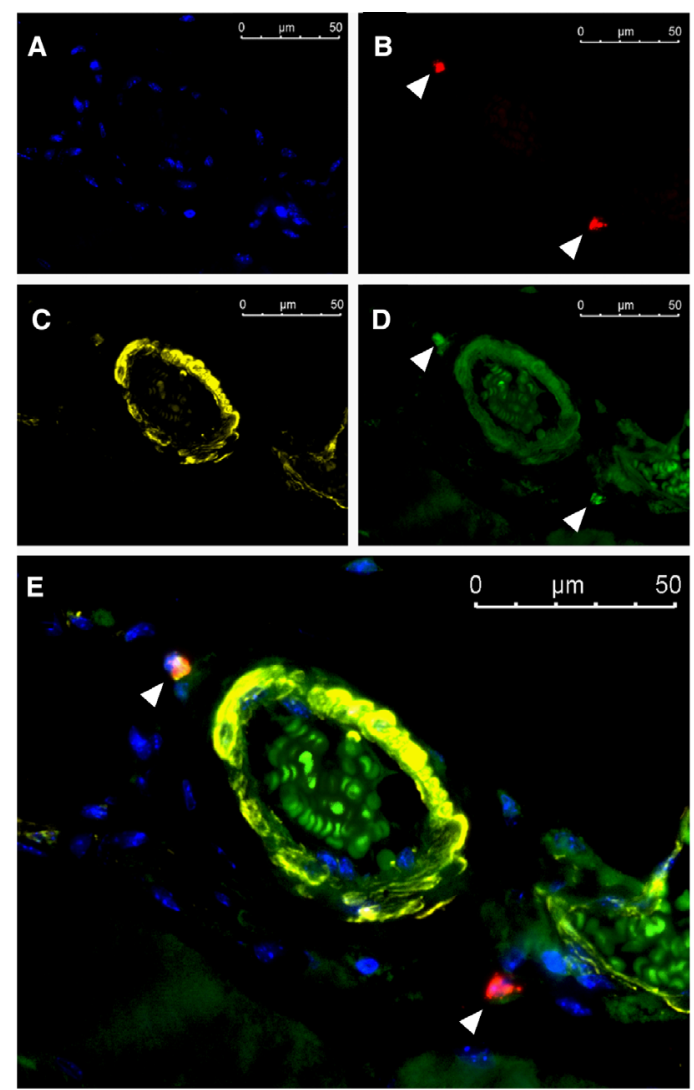

$\mathbf{F}$

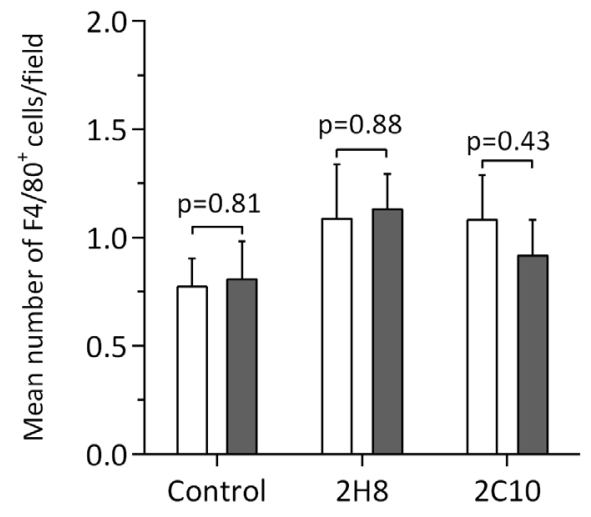

G

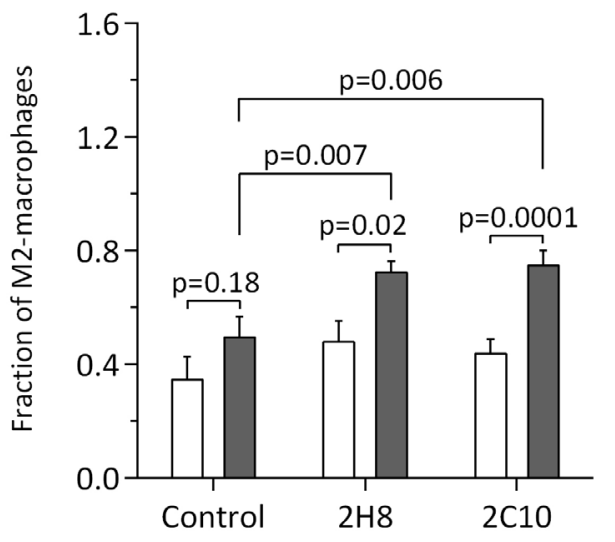

Sham

Ligation

ANOVA between

ligation groups $p=0.25$

ANOVA between

sham groups $p=0.49$

Figure 4. Perivascular macrophage characteristics. Analysis of perivascular macrophage characteristics by quadruple fluorescent immunohistochemistry. A-E, A typical example of an a arteriole with perivascular macrophages, stained for the pan-macrophage marker F4/80 (A), cell nuclei (B), SMA (smooth muscle actin; C), and M2 marker mannose receptor (D). E, Merged image. Total number of macrophages (F) and fraction of M2 macrophages $(\mathbf{G})$ were quantified. Animals used: control, $n=10 ; 2 C 10, n=11 ; 2 H 8, n=14$. ANOVA plus Dunnett test was used for analysis.

with stimulation with medium only. This upregulation was significantly reduced after the addition of either $2 \mathrm{H} 8$ or $2 \mathrm{C} 10$ to murine bone marrow-derived cells (Figure 6A-6C). An identical effect was demonstrated in isolated human monocytes, indicating that the antibody treatment directly affects these cells (Figure 6D-6F).

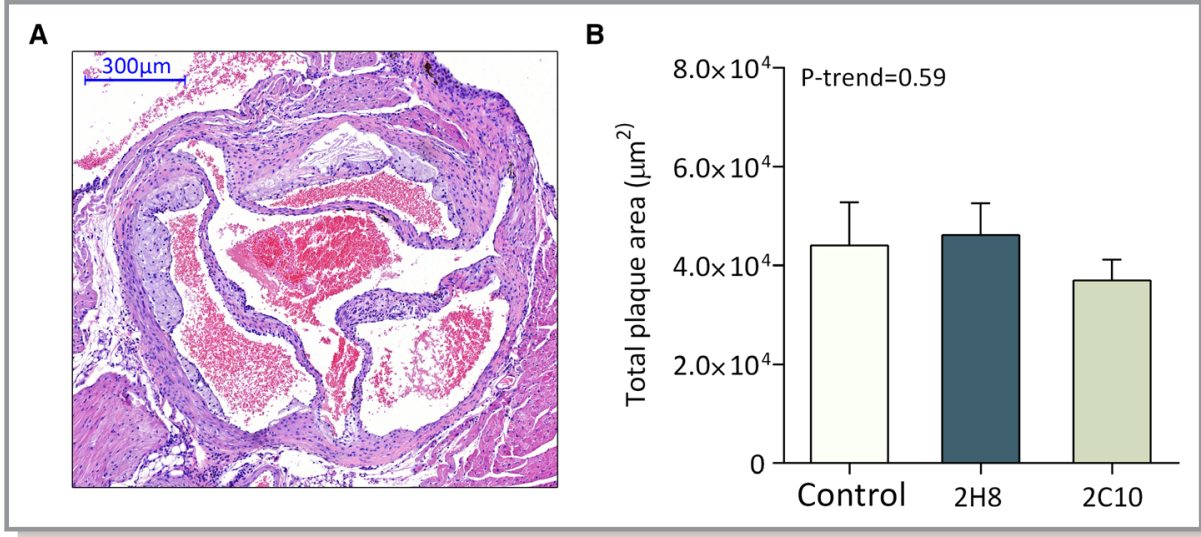

Figure 5. Atherosclerosis. Anti-Gal-2 treatment does not affect atherosclerosis. A, Representative microscopic images of hematoxylin and eosin-stained aortic root sections of Western dietfed LDLR-/-.Leiden mice: control, $n=10 ; 2 \mathrm{C} 10, n=13 ; 2 \mathrm{H} 8, \mathrm{n}=11$. Magnification $\times 9$. B. Plaque area in the aortic root of animals treated with control, $2 \mathrm{H} 8$, or $2 \mathrm{C} 10$ was comparable between groups using ANOVA. Gal-2 indicates galectin 2; LDLR-/-, low-density lipoprotein receptor-null. 


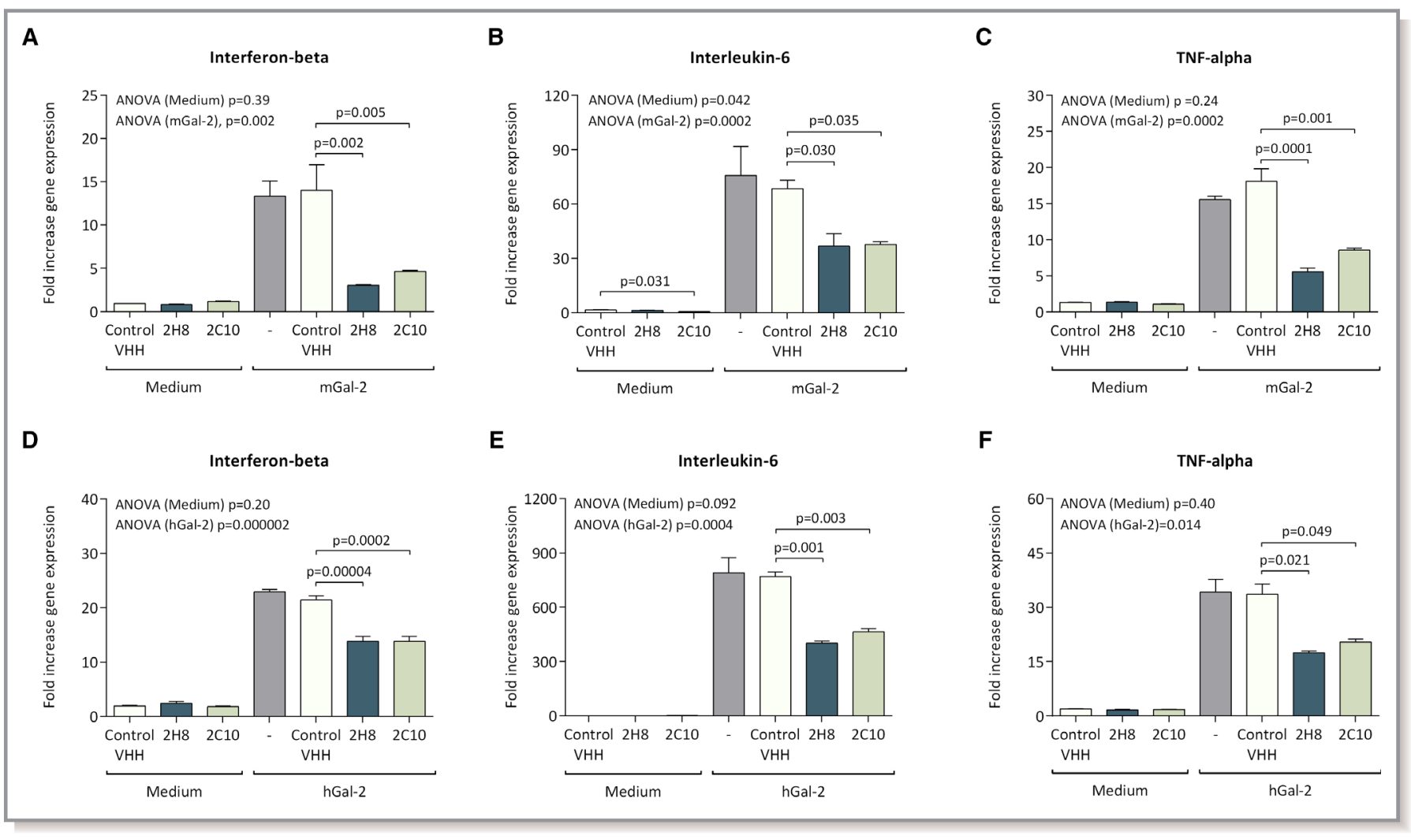

Figure 6. Gal-2-induced RNA-expression. RNA expression levels of murine isolated bone marrow effector cells (A-C) and human isolated monocytes (D-F). Cells (100 000 cells/well) were stimulated for 3 hours with medium only (calibrator sample, not shown), Gal-2, Gal-2 with $2 \mathrm{C} 10$ antibody, Gal-2 with $2 \mathrm{H} 8$ antibody, Gal-2 with an irrelevant control single-domain antibody (control VHH), $2 \mathrm{C} 10$ antibody alone, $2 \mathrm{H} 8$ antibody alone, or control VHH antibody alone. After stimulation, RNA expression of M1-associated genes IFN- $\beta$ (interferon $\beta$; $\mathbf{A}$ and $\mathbf{D}$ ), IL6 (interleukin 6; $\mathbf{B}$ and $\mathbf{E}$ ), and TNF- $\alpha$ (tumor necrosis factor $\alpha ; \mathbf{C}$ and $\mathbf{F}$ ) were quantified. Expression is displayed as fold increase to the calibrator sample (medium only) and relative to reference gene GAPDH. All experiments were executed in triplicate. Trend analysis was performed separately for samples stimulated with and without Gal-2. Post hoc analysis was performed with a Dunnett test using the control VHH samples as the reference group. Gal-2 indicates galectin 2; hGAL-2, human galectin 2; IFN- $\beta$, interferon $\beta$; IL6, interleukin 6; mGal-2, murine galectin 2; TNF- $\alpha$, tumor necrosis factor- $\alpha$; VHH, variable domain of heavy chains.

\section{Discussion}

In this study, we developed new single-domain antibodies against Gal-2 and investigated their effects in vitro on monocyte binding and in vivo on arteriogenesis and atherosclerosis. We show that both single-domain antibodies $2 \mathrm{H} 8$ and $2 \mathrm{C} 10$ strongly inhibit the binding of Gal-2 to monocytes in vitro and that treatment with these antibodies stimulates arteriogenesis in a murine hind limb model. This effect was related to an increase of perivascular M2 macrophages. The quantity of perivascular macrophages was not affected, suggesting that anti-Gal-2 does not attract more macrophages but rather causes a shift toward a proarteriogenic phenotype. In similar fashion, both VHH antibodies decrease the expression of Gal-2-induced proinflammatory and M1-associated cytokines. No effects on atherosclerosis were observed.

Gal-2 is expressed by inflammatory cells, such as lymphocytes $^{26,27}$ and monocytes. ${ }^{11,13}$ Previously we demonstrated that monocytes of patients with poor collateral artery growth show increased levels of Gal-2, ${ }^{11}$ which could be attributed to genomic variations. The antiarteriogenic properties of Gal-2 were subsequently confirmed in a murine hind limb model ${ }^{11}$ and could be ascribed to a macrophage shift toward the proinflammatory M1 phenotype. ${ }^{13}$ Consequently, we hypothesized that inhibition of Gal-2 would stimulate collateral artery growth and polarize macrophages into a proarteriogenic M2 phenotype.

Because Gal-2 acts mainly by the binding to the cell surface of monocytes, ${ }^{13,28}$ we postulated that antibodies inhibiting Gal-2 binding to monocytes could limit the downstream effects of Gal-2. To test this, and because of the unavailability of blocking antibodies against Gal-2, we developed single-domain antibodies by immunizing llamas. These antibodies lack a light chain, as seen in conventional antibodies, and thus consist only of the VHHs (or VHH antibodies). This structural alteration strongly limits the molecular size of VHHs without compromising antigen specificity and affinity. ${ }^{29}$ In addition, VHHs can 
resist low-pH conditions, ${ }^{29}$ which possibly enables oral application and distinguishes VHHs from conventional antibodies. In our study we used intraperitoneal rather than oral administration to achieve equal dosage between mice. Moreover, injections were done daily to compensate for the relatively high clearance of $\mathrm{VHHs} .{ }^{14}$ However, proper antigen affinity is paramount for in vivo effects; therefore, we selected only those antibodies that showed the highest affinity for mGal-2 and hGal-2. Furthermore, we investigated binding inhibition on monocytes because they play a key role in collateral vessel growth. ${ }^{9}$ After an increase in shear stress, the activated endothelium of collateral vessels attracts monocytes, which migrate into the perivascular space, where they become macrophages. ${ }^{30}$ Here macrophages produce several growth factors, such as granulocyte-macrophage colony-stimulating factor (GM-CSF), ${ }^{31}$ monocyte chemoattractant protein 1 (MCP$1)^{32}$ and placental growth factor (PGF), ${ }^{33}$ all of which have proarteriogenic effects, mostly by attracting and activating monocytes and macrophages. Data from our flow cytometry analyses show that the 3 antibodies with the highest affinity inhibit the binding of Gal-2 to monocytes by $\approx 90 \%$. This significantly reduces the expression of Gal-2-related downstream genes, which are all characteristic for the proinflammatory M1 phenotype and are associated with poor arteriogenesis.

Conversely, M2 macrophages are associated with improved collateral artery growth ${ }^{34}$ and postischemic tissue repair. ${ }^{35}$ Adjusting the balance between $\mathrm{M} 1$ and $\mathrm{M} 2$ is an interesting target for arteriogenic therapy. In a murine prolyl hydroxylase domain-containing protein 2 (PHD2) knockout model, skewing macrophages into an M2 phenotype increased collateral vessel growth and prevented ischemia. ${ }^{36}$ In addition, local administration with endogenous M2 macrophages increases arteriogenesis in mice. ${ }^{37} \mathrm{Gal}-2$ skews macrophages into the M1 phenotype ${ }^{13}$ and inhibits arteriogenesis. ${ }^{11}$ In this study we showed that treatment with anti-Gal-2 antibodies skewed macrophages into the M2 phenotype, which resulted in an increased arteriogenic response on femoral artery ligation. Macrophage polarization is also influenced by another galectin family member, Gal-3, which influences macrophage activation, ${ }^{38,39}$ Interestingly, Gal-3 expression is increased in M2 macrophages, unlike Gal-2, which skews macrophages to the M2 phenotype. This opposite effect can perhaps be explained by different binding mechanisms of Gal-3 and Gal-2. ${ }^{40}$ Data on the role of Gal-3 on collateral artery growth are lacking. Current research is focused on Gal-2 for the stimulation of arteriogenesis, based on whole-genome analysis of patients with poorand well-developed collateral arteries ${ }^{11}$ that explicitly shows a role for $\mathrm{Gal}-2$.

A problem of proarteriogenic therapy is the simultaneous stimulation of atherosclerosis. Previous studies have shown that proarteriogenic compounds also can induce progression of plaque formation, ${ }^{4-43}$ antagonizing their beneficial effects. However, the anti-inflammatory characteristics of M2 macrophages have been linked to increased plaque stability. ${ }^{44,45}$ In the current study, which uses hypercholesterolemic, Western diet-fed LDLR-/-.Leiden mice, ${ }^{20}$ no change in atherosclerotic plaque area following anti-Gal-2 treatment could be demonstrated. It must be noted that a 2-week treatment is relatively short to reveal any effect on atherosclerosis, but plaque area was not our primary end point in this proof-of-principle study.

The perfusion data from our study also show in the control animals that perfusion restoration ceases to continue after 7 days, whereas perfusion restoration in the anti-Gal-2treated animals progresses beyond 1 week. The halted perfusion restoration could be a result of the increased levels of M1 macrophages, which in turn could be attributed to the hypercholesterolemia ${ }^{46}$ of these Western diet-fed LDLR-/ -.Leiden mice. ${ }^{20,47}$ It should be noted that patients who would benefit from collateral-stimulating therapies typically have atherosclerotic disease. Moreover, patients with poorly developed collateral circulation particularly show increased levels of M1-associated cytokines ${ }^{10,48}$ and thus could benefit from anti-Gal-2 therapy. In the antibody-treated animals, perfusion continued to restore, suggesting that collateral arteries were still actively developing at the time of tissue harvesting, which is in line with the difference in $M 2$ macrophages. This result is further validated by our in vitro data showing that anti-Gal-2 antibodies strongly decrease M1-associated cytokine production, a finding in line with previous results. ${ }^{13}$

This study has some limitations. First, we did not use an irrelevant $\mathrm{VHH}$ as a control in the in vivo experiments. The control we used in the in vitro experiments was a specific antiHIV VHH, for which the in vivo effect was unclear. Consequently, we used only the vehicle of the VHHs as a control to equalize the effect of the injections between all groups. Moreover, data from the functional mRNA assay (Figure 6) showed that treatment with the control VHH had no effect on cytokine expression, indicating that the effects of antibodies $2 \mathrm{H} 8$ and $2 \mathrm{C} 10$ were specific for anti-Gal-2 inhibition. Second, we calculated the treatment dosage of the $\mathrm{VHH}$ antibodies for the in vivo experiments based on previous experiments with a conventional monoclonal antibody. ${ }^{22}$ We corrected for molecular weight and administered the in vivo $\mathrm{VHH}$ treatment daily; however, because of high renal clearance, we assumed the blocking capacity would be comparable to conventional antibodies. The latter is in strengthened by $>90 \%$ monocyte binding inhibition, as shown in vitro. Third, only mRNA analyses were performed to study downstream effects. Although protein assays would be insightful, available tissue quantity did not allow for both assays. The mRNA measurements were preferred over protein data, given the more quantitative nature. Finally, the follow-up period is relatively 
short, which limits the investigation of long-term effects. Although this study is a proof-of-principle for the arteriogenic effect of anti-Gal-2 treatment, data from Table 2 show that the difference in perfusion restoration between the antibody groups and control is larger at 14 days than at 1 week, suggesting that treatment effect is progressive over time. From a clinical perspective, it would be interesting to determine the posttreatment stability of the enhanced collateral circulation. Although there are no data on pharmacologically induced arteriogenesis, studies in patients with peripheral artery disease show that a period of physical exercise has a persistent, long-term effect, even after the training program has ended. ${ }^{49,50}$ This finding suggests that collateral arteries, once well developed, have a lasting effect. The long-term effects of anti-Gal-2 treatment, including on atherosclerosis, are outside the scope of the current article.

In conclusion, this report is the first on the use of llamaderived single-domain antibodies to stimulate arteriogenesis. Anti-Gal-2 treatment increases perfusion restoration on femoral artery ligation in a murine model. This is accompanied by an increase in the fraction of proarteriogenic $M 2$ macrophages. No effects on atherosclerosis were observed.

\section{Acknowledgments}

We would like to acknowledge Elsbet Pieterman and Robert Kleemann of TNO Metabolic Health Research for generously supplying us with the LDLR-/-.Leiden mice. We would also like to thank Cansu Yildirim for the production of the recombinant murine and human Gal-2 (galectin 2).

\section{Sources of Funding}

The current study was completely funded by the VU University Medical Center and the Academic Medical Center, both located in Amsterdam, The Netherlands.

\section{Disclosures}

None.

\section{References}

1. Schaper W, Buschmann I. Arteriogenesis, the good and bad of it. Eur Heart J. 1999;20:1297-1299.

2. Seiler C, Stoller M, Pitt B, Meier P. The human coronary collateral circulation: development and clinical importance. Eur Heart J. 2013;34:2674-2682.

3. Ripley DP, Gosling OE, Bhatia L, Peebles CR, Shore AC, Curzen N, Bellenger NG. The relationship between the contralateral collateral supply and myocardial viability on cardiovascular magnetic resonance: can the angiogram predict functional recovery? Int J Cardiol. 2014;177:362-367.

4. Hara M, Sakata Y, Nakatani D, Suna S, Nishino M, Sato H, Kitamura T, Nanto S, Hori M, Komuro I; OACIS Investigators. Impact of coronary collaterals on inhospital and 5-year mortality after ST-elevation myocardial infarction in the contemporary percutaneous coronary intervention era: a prospective observational study. BMJ Open. 2016;6:e011105.
5. Meier P, Gloekler S, Zbinden R, Beckh S, de Marchi SF, Zbinden S, Wustmann K, Billinger M, Vogel R, Cook S, Wenaweser P, Togni M, Windecker S, Meier B, Seiler C. Beneficial effect of recruitable collaterals: a 10-year follow-up study in patients with stable coronary artery disease undergoing quantitative collateral measurements. Circulation. 2007;116:975-983.

6. Yetkin E, Topal E, Erguzel N, Senen K, Heper G, Waltenberger J. Diabetes mellitus and female gender are the strongest predictors of poor collateral vessel development in patients with severe coronary artery stenosis. Angiogenesis. 2015;18:201-207.

7. Turhan H, Yasar AS, Erbay AR, Yetkin E, Sasmaz H, Sabah I. Impaired coronary collateral vessel development in patients with metabolic syndrome. Coron Artery Dis. 2005;16:281-285.

8. Yilmaz MB, Caldir V, Guray Y, Guray U, Altay H, Demirkan B, Cay S, Kisacik HL, Korkmaz S. Relation of coronary collateral vessel development in patients with a totally occluded right coronary artery to the metabolic syndrome. Am J Cardiol. 2006;97:636-639.

9. Bergmann CE, Hoefer IE, Meder B, Roth H, van Royen N, Breit SM, Jost MM, Aharinejad S, Hartmann S, Buschmann IR. Arteriogenesis depends on circulating monocytes and macrophage accumulation and is severely depressed in op/op mice. J Leukoc Biol. 2006;80:59-65.

10. Schirmer SH, Fledderus JO, Bot PT, Moerland PD, Hoefer IE, Baan J Jr, Henriques JP, van der Schaaf RJ, Vis MM, Horrevoets AJ, Piek JJ, van Royen N. Interferon-beta signaling is enhanced in patients with insufficient coronary collateral artery development and inhibits arteriogenesis in mice. Circ Res. 2008;102:1286-1294.

11. van der Laan AM, Schirmer SH, de Vries MR, Koning JJ, Volger OL, Fledderus JO, Bastiaansen AJ, Hollander MR, Baggen JM, Koch KT, Baan J Jr, Henriques JP, van der Schaaf RJ, Vis MM, Mebius RE, van der Pouw Kraan TC, Quax PH, Piek JJ, Horrevoets AJ, van Royen N. Galectin-2 expression is dependent on the rs7291467 polymorphism and acts as an inhibitor of arteriogenesis. Eur Heart J. 2012;33:1076-1084.

12. van der Hoeven NW, Hollander MR, Yildirim C, Jansen MF, Teunissen PF, Horrevoets AJ, van der Pouw Kraan TC, van Royen N. The emerging role of galectins in cardiovascular disease. Vascul Pharmacol. 2016;81:31-41.

13. Yildirim C, Vogel DY, Hollander MR, Baggen JM, Fontijn RD, Nieuwenhuis S, Haverkamp A, de Vries MR, Quax PH, Garcia-Vallejo JJ, van der Laan AM, Dijkstra CD, van der Pouw Kraan TC, van Royen N, Horrevoets AJ. Galectin-2 induces a proinflammatory, anti-arteriogenic phenotype in monocytes and macrophages. PLoS One. 2015;10:e0124347.

14. Harmsen MM, De Haard HJ. Properties, production, and applications of camelid single-domain antibody fragments. Appl Microbiol Biotechnol. 2007;77:13-22.

15. Dumoulin M, Conrath K, Van Meirhaeghe A, Meersman F, Heremans K, Frenken LG, Muyldermans S, Wyns L, Matagne A. Single-domain antibody fragments with high conformational stability. Protein Sci. 2002;11:500-515.

16. Harmsen MM, Ruuls RC, Nijman IJ, Niewold TA, Frenken LG, de Geus B. Llama heavy-chain $\mathrm{V}$ regions consist of at least four distinct subfamilies revealing novel sequence features. Mol Immunol. 2000;37:579-590.

17. Lotfi S, Patel AS, Mattock K, Egginton S, Smith A, Modarai B. Towards a more relevant hind limb model of muscle ischaemia. Atherosclerosis. 2013;227:1-8.

18. Strokappe N, Szynol A, Aasa-Chapman M, Gorlani A, Forsman Quigley A, Hulsik DL, Chen L, Weiss R, de Haard H, Verrips T. Llama antibody fragments recognizing various epitopes of the CD4bs neutralize a broad range of HIV-1 subtypes A, B and C. PLoS One. 2012;7:e33298.

19. Helisch A, Wagner S, Khan N, Drinane M, Wolfram S, Heil M, Ziegelhoeffer T, Brandt U, Pearlman JD, Swartz HM, Schaper W. Impact of mouse strain differences in innate hindlimb collateral vasculature. Arterioscler Thromb Vasc Biol. 2006;26:520-526.

20. Morrison MC, Kleemann R, van Koppen A, Hanemaaijer R, Verschuren L. Key inflammatory processes in human NASH are reflected in $\operatorname{Ldlr}(-/-)$.Leiden mice: a translational gene profiling study. Front Physiol. 2018;9:132.

21. Emini Veseli B, Perrotta P, De Meyer GRA, Roth L, Van der Donckt C, Martinet W, De Meyer GRY. Animal models of atherosclerosis. Eur J Pharmacol. 2017;816:3-13.

22. Teunissen PF, Boshuizen MC, Hollander MR, Biesbroek PS, van der Hoeven NW, Mol JQ, Gijbels MJ, van der Velden S, van der Pouw Kraan TC, Horrevoets AJ, de Winther MP, van Royen N. MAb therapy against the IFN-alpha/beta receptor subunit 1 stimulates arteriogenesis in a murine hindlimb ischaemia model without enhancing atherosclerotic burden. Cardiovasc Res. 2015;107:255-266.

23. Limbourg A, Korff T, Napp LC, Schaper W, Drexler H, Limbourg FP. Evaluation of postnatal arteriogenesis and angiogenesis in a mouse model of hind-limb ischemia. Nat Protoc. 2009;4:1737-1746.

24. Ruijter JM, Pfaffl MW, Zhao S, Spiess AN, Boggy G, Blom J, Rutledge RG, Sisti D, Lievens A, De Preter K, Derveaux S, Hellemans J, Vandesompele J. 
Evaluation of qPCR curve analysis methods for reliable biomarker discovery: bias, resolution, precision, and implications. Methods. 2013;59:32-46.

25. Wang N, Liang $\mathrm{H}$, Zen $\mathrm{K}$. Molecular mechanisms that influence the macrophage M1-M2 polarization balance. Front Immunol. 2014;5:614.

26. Sturm A, Lensch M, Andre S, Kaltner H, Wiedenmann B, Rosewicz S, Dignass AU, Gabius HJ. Human galectin-2: novel inducer of T cell apoptosis with distinct profile of caspase activation. J Immunol. 2004;173:3825-3837.

27. Paclik D, Berndt U, Guzy C, Dankof A, Danese S, Holzloehner P, Rosewicz S, Wiedenmann B, Wittig BM, Dignass AU, Sturm A. Galectin-2 induces apoptosis of lamina propria $T$ lymphocytes and ameliorates acute and chronic experimental colitis in mice. J Mol Med (Berl). 2008;86:1395-1406.

28. Si Y, Feng S, Gao J, Wang Y, Zhang Z, Meng Y, Zhou Y, Tai G, Su J. Human galectin-2 interacts with carbohydrates and peptides non-classically: new insight from X-ray crystallography and hemagglutination. Acta Biochim Biophys Sin (Shanghai). 2016;48:939-947.

29. Hussack G, Hirama T, Ding W, Mackenzie R, Tanha J. Engineered single-domain antibodies with high protease resistance and thermal stability. PLOS One. 2011;6:e28218.

30. Schaper J, Konig R, Franz D, Schaper W. The endothelial surface of growing coronary collateral arteries. Intimal margination and diapedesis of monocytes. A combined SEM and TEM study. Virchows Arch A Pathol Anat Histol. 1976;370:193-205.

31. Buschmann IR, Hoefer IE, van Royen N, Katzer E, Braun-Dulleaus R, Heil M, Kostin S, Bode C, Schaper W. GM-CSF: a strong arteriogenic factor acting by amplification of monocyte function. Atherosc/erosis. 2001;159:343-356.

32. Shyy YJ, Hsieh HJ, Usami S, Chien S. Fluid shear stress induces a biphasic response of human monocyte chemotactic protein 1 gene expression in vascular endothelium. Proc Natl Acad Sci USA. 1994;91:4678-4682.

33. Pipp F, Heil M, Issbrucker K, Ziegelhoeffer T, Martin S, van den Heuvel J, Weich $H$, Fernandez B, Golomb G, Carmeliet P, Schaper W, Clauss M. VEGFR-1selective VEGF homologue PIGF is arteriogenic: evidence for a monocytemediated mechanism. Circ Res. 2003;92:378-385.

34. Troidl C, Jung G, Troidl K, Hoffmann J, Mollmann H, Nef H, Schaper W, Hamm CW, Schmitz-Rixen T. The temporal and spatial distribution of macrophage subpopulations during arteriogenesis. Curr Vasc Pharmacol. 2013;11:5-12.

35. Troidl C, Mollmann H, Nef H, Masseli F, Voss S, Szardien S, Willmer M, Rolf A, Rixe J, Troidl K, Kostin S, Hamm C, Elsasser A. Classically and alternatively activated macrophages contribute to tissue remodelling after myocardial infarction. J Cell Mol Med. 2009;13:3485-3496.

36. Takeda Y, Costa S, Delamarre E, Roncal C, Leite de Oliveira R, Squadrito ML, Finisguerra V, Deschoemaeker S, Bruyere F, Wenes M, Hamm A, Serneels J, Magat J, Bhattacharyya T, Anisimov A, Jordan BF, Alitalo K, Maxwell P, Gallez B, Zhuang ZW, Saito Y, Simons M, De Palma M, Mazzone M. Macrophage skewing by Phd2 haplodeficiency prevents ischaemia by inducing arteriogenesis. Nature. 2011;479:122-126.

37. Jetten N, Donners MM, Wagenaar A, Cleutjens JP, van Rooijen N, de Winther MP, Post MJ. Local delivery of polarized macrophages improves reperfusion recovery in a mouse hind limb ischemia model. PLOS One. 2013;8:e68811.
38. Dragomir AC, Sun R, Choi H, Laskin JD, Laskin DL. Role of galectin-3 in classical and alternative macrophage activation in the liver following acetaminophen intoxication. J Immunol. 2012;189:5934-5941.

39. Novak R, Dabelic S, Dumic J. Galectin-1 and galectin-3 expression profiles in classically and alternatively activated human macrophages. Biochim Biophys Acta. 2012;1820:1383-1390.

40. Stowell SR, Arthur CM, Mehta P, Slanina KA, Blixt O, Leffler H, Smith DF, Cummings RD. Galectin-1, -2 , and -3 exhibit differential recognition of sialylated glycans and blood group antigens. I Biol Chem. 2008;283:1010910123.

41. Grundmann S, Hoefer I, Ulusans S, Bode C, Oesterle S, Tijssen JG, Piek JJ, Buschmann I, van Royen N. Granulocyte-macrophage colony-stimulating factor stimulates arteriogenesis in a pig model of peripheral artery disease using clinically applicable infusion pumps. J Vasc Surg. 2006;43:1263-1269.

42. van Royen N, Hoefer I, Bottinger M, Hua J, Grundmann S, Voskuil M, Bode C, Schaper W, Buschmann I, Piek JJ. Local monocyte chemoattractant protein-1 therapy increases collateral artery formation in apolipoprotein E-deficient mice but induces systemic monocytic CD11b expression, neointimal formation, and plaque progression. Circ Res. 2003;92:218-225.

43. Subramanian M, Thorp E, Tabas I. Identification of a non-growth factor role for GM-CSF in advanced atherosclerosis: promotion of macrophage apoptosis and plaque necrosis through IL-23 signaling. Circ Res. 2015;116:e13-e24.

44. Moore KJ, Sheedy FJ, Fisher EA. Macrophages in atherosclerosis: a dynamic balance. Nat Rev Immunol. 2013;13:709-721.

45. Shaikh S, Brittenden J, Lahiri R, Brown PA, Thies F, Wilson HM. Macrophage subtypes in symptomatic carotid artery and femoral artery plaques. Eur J Vasc Endovasc Surg. 2012;44:491-497.

46. Fadini GP, Simoni F, Cappellari R, Vitturi N, Galasso S, Vigili de Kreutzenberg S, Previato L, Avogaro A. Pro-inflammatory monocyte-macrophage polarization imbalance in human hypercholesterolemia and atherosclerosis. Atherosclerosis. 2014;237:805-808.

47. Liang W, Menke AL, Driessen A, Koek GH, Lindeman JH, Stoop R, Havekes LM, Kleemann R, van den Hoek AM. Establishment of a general NAFLD scoring system for rodent models and comparison to human liver pathology. PLOS One. 2014;9:e115922.

48. Hakimzadeh N, Elias J, Wijntjens GWM, Theunissen R, van Weert A, Smulders MW, van den Akker N, Moerland PD, Verberne HJ, Hoebers LP, Henriques JPS, van der Laan AM, Ilhan M, Post M, Bekkers S, Piek JJ. Monocytic microRNA profile associated with coronary collateral artery function in chronic total occlusion patients. Sci Rep. 2017;7:1532.

49. Gardner AW, Katzel LI, Sorkin JD, Goldberg AP. Effects of long-term exercise rehabilitation on claudication distances in patients with peripheral arterial disease: a randomized controlled trial. J Cardiopulm Rehabil. 2002;22:192198.

50. Murphy TP, Cutlip DE, Regensteiner JG, Mohler ER III, Cohen DJ, Reynolds MR, Massaro JM, Lewis BA, Cerezo J, Oldenburg NC, Thum CC, Jaff MR, Comerota AJ, Steffes MW, Abrahamsen IH, Goldberg S, Hirsch AT. Supervised exercise, stent revascularization, or medical therapy for claudication due to aortoiliac peripheral artery disease: the CLEVER study. J Am Coll Cardiol. 2015;65:999-1009. 
SUPPLEMENTAL MATERIAL 
Table S1. Oligonucleotides used for real-time RT-PCR.

\begin{tabular}{|c|c|c|}
\hline Gene & Forward primer sequence & Backward primer sequence \\
\hline \multicolumn{3}{|l|}{ HUMAN } \\
\hline $\begin{array}{l}\text { GAPDH } \\
\text { (Sigma) }\end{array}$ & GAAGGTGAAGGTCGGAGTCAAC & CAGAGTTAAAAGCAGCCCTGGT \\
\hline $\begin{array}{l}\text { TNF-A } \\
\text { (Invitrogen) }\end{array}$ & GGCGTGGAGCTGAGAGAT & TGGTAGGAGACGGCGATG \\
\hline $\begin{array}{l}\text { IL6 } \\
\text { (Invitrogen) }\end{array}$ & GAGTAGTGAGGAACAAGCCAG & TTGTCATGTCCTGCAGCC \\
\hline $\begin{array}{l}\text { IFNB } \\
\text { (Invitrogen) }\end{array}$ & ACGCCGCATTGACCATCTAT & GTCTCATTCCAGCCAGTGCT \\
\hline \multicolumn{3}{|l|}{ MURINE } \\
\hline $\begin{array}{l}\text { GAPDH } \\
\text { (Invitrogen) }\end{array}$ & CAACTCACTCAAGATTGTCAGCAA & TGGCAGTGATGGCATGGA \\
\hline $\begin{array}{l}\text { TNF-A } \\
\text { (Invitrogen) }\end{array}$ & САТСTTCTCAAAATTCGAGTGACAA & TGGGAGTAGACAAGGTACAACCC \\
\hline $\begin{array}{l}\text { IL6 } \\
\text { (Invitrogen) }\end{array}$ & GCTACCAAACTGGATATAATCAGGAAA & CTTGTTATCTTTTAAGTTGTTCTTCATGTACTC \\
\hline $\begin{array}{l}\text { IFNB } \\
\text { (Invitrogen) }\end{array}$ & GCTATTACTGGAGGGTGCAAAGG & GTCTTCGAATGATGAGAAAGTTCCT \\
\hline
\end{tabular}

GAPDH= Glyceraldehyde 3-phosphate dehydrogenase, TNF-A = tumor necrosis factor alpha, IL6 = interleukin 6, IFNB = interferon beta. 
Table S2. ELISA Binding assay of single domain antibodies with human and murine Galectin-2.

\begin{tabular}{|c|c|c|c|c|c|}
\hline \multicolumn{3}{|c|}{ Cross-binding VHHs } & \multicolumn{3}{|c|}{ Human specific VHHs } \\
\hline \multirow{2}{*}{ VHH name } & \multicolumn{2}{|c|}{ Binding reagent } & \multirow{2}{*}{ VHH name } & \multicolumn{2}{|c|}{ Binding reagent } \\
\hline & hGal-2 & mGal-2 & & hGal-2 & mGal-2 \\
\hline VG2-2B11 & 0.99 & 1.56 & VG2-2B10 & 0.50 & 0.02 \\
\hline VG2-2A7 & 0.92 & 1.32 & VG2-2D8 & 0.52 & 0.04 \\
\hline VG2-2B12 & 0.88 & 0.81 & VG2-2D11 & 0.51 & 0.05 \\
\hline VG2-1D9 & 0.87 & 0.87 & VG2-2E11 & 0.43 & 0.06 \\
\hline VG2-2C8 & 0.72 & 0.64 & VG2-2H4 & 0.09 & -0.01 \\
\hline VG2-2E8 & 0.71 & 0.47 & & & \\
\hline VG2-2H8 & 0.67 & 0.59 & & & \\
\hline VG2-2C9 & 0.64 & 0.81 & \multicolumn{3}{|c|}{ Mouse specific VHHs } \\
\hline VG2-2F9 & 0.62 & 0.67 & \multirow{2}{*}{ VHH name } & \multicolumn{2}{|c|}{ Binding reagent } \\
\hline VG2-1G11 & 0.61 & 0.82 & & hGal-2 & mGal-2 \\
\hline VG2-2G8 & 0.57 & 0.31 & VG2-1A9 & -0.02 & 0.39 \\
\hline VG2-2G7 & 0.53 & 0.61 & VG2-1B11 & -0.02 & 0.72 \\
\hline VG2-1F12 & 0.53 & 0.44 & VG2-1C11 & -0.02 & 0.79 \\
\hline VG2-2F7 & 0.51 & 0.28 & VG2-1E7 & -0.01 & 0.77 \\
\hline VG2-2H7 & 0.51 & 0.51 & VG2-1G12 & -0.01 & 1.29 \\
\hline VG2-2C12 & 0.51 & 0.30 & & & \\
\hline VG2-2C10 & 0.45 & 0.63 & & & \\
\hline VG2-2D9 & 0.45 & 0.28 & & & \\
\hline VG2-2B8 & 0.41 & 0.32 & & & \\
\hline VG2-2F11 & 0.40 & 0.21 & & & \\
\hline VG2-2E9 & 0.40 & 0.27 & & & \\
\hline VG2-2G9 & 0.39 & 0.23 & & & \\
\hline VG2-1F10 & 0.35 & 0.56 & & & \\
\hline VG2-1E11 & 0.33 & 0.18 & & & \\
\hline VG2-2E7 & 0.31 & 0.38 & & & \\
\hline VG2-1A8 & 0.30 & 0.29 & & & \\
\hline VG2-2B7 & 0.29 & 0.38 & & & \\
\hline VG2-2A12 & 0.28 & 0.19 & & & \\
\hline VG2-1D11 & 0.26 & 0.22 & & & \\
\hline VG2-2C7 & 0.25 & 0.35 & & & \\
\hline VG2-2H1 & 0.19 & 0.18 & & & \\
\hline
\end{tabular}

$\mathrm{VHH}=$ Single domain antibody, mGal-2 = murine Galectin-2, hGal-2 = human Galectin 
Figure S1. Single domain antibody purity after subcloning.

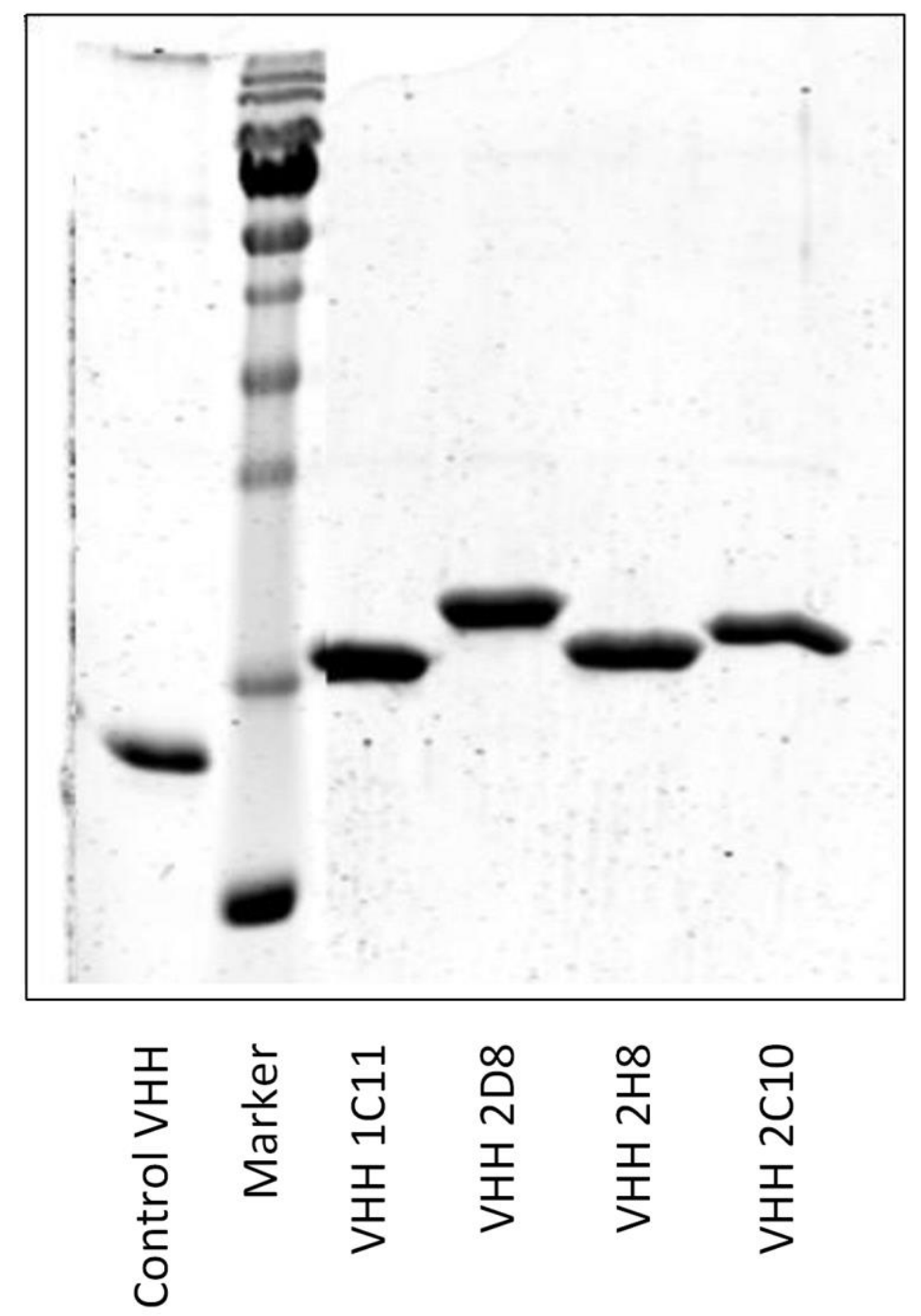

Purity of four selected single domain antibodies (VHHs) after subcloning, demonstrated by SDSPAGE gel electrophoresis. 